CUM LAUDE

Revista del Doctorado en Derecho

Facultad de Derecho y Ciencias Sociales y Políticas UNNE

$\mathrm{N}^{\circ} 4$ - Abril 2017

Corrientes - Argentina

ISSN: 2422-6408

info@revistacumlaude.com

FECHA DE RECEPCIÓN: 10/09/2015

FECHA DE ACEPTACIÓN: 27/04/2016

\title{
LA DEMANDA DE CONFESIÓN Y EL PROCESO PENAL
}

\section{Fernando Carbajal}

\section{UNIVERSIDAD NACIONAL DEL NORDESTE}

\section{RESUMEN}

Es un hecho histórico que en nuestros sistemas procesales penales tradicionales existe una demanda de veridicción, de confesión. El sistema pretende y espera que el acusado confiese su crimen. Esta demanda es de origen religioso, se institucionalizo con la inquisición y supero las reformas del siglo XIX aunque resignificada en su finalidad y método, pero persistente como aspiración del sistema de juzgamiento penal.

La aprobación del nuevo código procesal penal de la Nación Ley 27.063 ha modificado de manera sustancial el régimen de declaración del imputado en el proceso penal, al haber eliminado el acto de citación a prestar la declaración, la cual se halla prevista como un acto voluntario del acusado. 


\section{LA DEMANDA DE CONFESIÓN Y EL PROCESO PENAL}

¿Ha abandonado el proceso penal la demanda de confesión? Afirmamos que sí, y las razones de este cambio, su trascendencia, y su impacto sobre la lucha cultural entre la inquisición y lo acusatorio, son el objetivo de este trabajo.

Cultura inquisitiva versus contracultura acusatoria y adversarial; encuentran en el declaración del imputado en el proceso uno punto de discusión con enormes implicancias sistémicas.

\section{Palabras Clave}

Acusatorio - inquisitivo - veridicción - confesión

\section{Abstract}

It is a historical fact that in our traditional "criminal justice procedural system" there is a big demand for veridiction, for confession. The system pretends and hopes that the accused will confess to his crime. This demand has a religious origin, it has been institutionalized by the inquisition and it has overcomed the reforms of the XIX century, although revamped on it's purpose and method; but persistent as a goal in the system of criminal prosecution.

The approval of the new Code of Criminal Procedure (law 27.063) has substantially changed the declaratory scheme of the accused in criminal proceedings, having eliminated the writ of summons to testify which is foreseen as a voluntary act of the accused.

Has the criminal justice procedural system relinquished the demand for confession? We say yes, and the reasons for this change, it's transcendence, and it's 
impact on the cultural fight between the inquisition and the accusatory are the aim of this study.

Inquisitive culture vs. accusatorial and adversarial counter; they find in the accused's statement during the process a point of debate with enormous systemic implications.

\section{KEYWORDS}

Accusatory - inquisitive - veridiction - confession

\section{VERIDICCION $^{1}$ Y PROCESO $^{2}$}

El proceso penal pretende que el imputado confiese el crimen del cual se lo acusa. Esta exigencia está centralmente establecida en el sistema inquisitivo, el tradicional y también sus versiones atenuadas como el llamado sistema mixto, al cual preferimos denominar inquisitivo atenuado.

\footnotetext{
${ }^{1}$ El término veridicción no figura en el diccionario, sin embargo Foucault lo utiliza en su obra. Hemos consultado a la Real Academia Española quien nos respondiera en los siguientes términos: "Estimado Sr. Carbajal: En relación con su consulta le remitimos la siguiente información: El término veridicción no pertenece a la lengua general, por lo que no aparece recogido en los diccionarios generales de lengua, como el DRAE. No obstante, es posible encontrar documentación de su uso en textos especializados. Se trata de un extranjerismo, procedente del término inglés veridiction, que, según la documentación disponible a nuestro alcance, parece que el propio Michel Foucault acuñó. Con respecto a la terminología que pertenece a un ámbito de especialidad, es la comunidad científica la que valida con el uso la creación de un término nuevo. Reciba un cordial saludo. Departamento de «Español al día» Real Academia Española. Por su parte el inglés veridiction no tiene una acepción equivalente en el castellano (según http://www.oxforddictionaries.com/) siendo su significado "A statement that is true according to the worldview of a particular subject" (www.yourdictionary.com) cuya traducción aproximada seria "una declaración de lo que es cierto sobre una tema desde la perspectiva de quien formula esa declaración"(traducción del autor). De nuestra parte la utilizamos en la acepción de Foucault: "acto de decir verdad"(Foucault 2013.29)
} 


\section{LA DEMANDA DE CONFESIÓN Y EL PROCESO PENAL}

La aprobación del nuevo Código Procesal Penal nacional, Ley 27.063, ha venido a instaurar en el orden federal, como lo hicieran antes algunas provincias argentinas, el sistema de juzgamiento penal previsto en la Constitución Nacional: acusatorio y adversarial. Por ello queremos abordar ahora, aunque más no sea brevemente, de donde emerge históricamente esa demanda de veridicción que la administración de justicia, de diversa forma y con diferentes modos, le exige al acusado, y cuál es el impacto del nuevo modelo de juzgamiento penal.

Y para ello abrevamos de Michel Foucault quien en las conocidas conferencias de Lovaina, que dictó en esa ciudad belga entre abril y mayo de 1981, ha analizado, con su habitual profundidad histórica y filosófica, la función que la confesión ha cumplido en la justicia, desde su nacimiento en las prácticas religiosas, su institucionalización y su posterior traspaso a las instituciones judiciales.

La veridicción es, en la tradición cristiana, anterior al establecimiento de la inquisición como institución de administración del poder jurisdiccional y proviene de la práctica religiosa del monacato y vinculada de manera directa a la penitencia. "La veridicción era de gran importancia en la práctica y la institución de la penitencia primitiva" (Foucault, 2013, p.121) quien vincula esta práctica con un término de origen griego que adquiere importancia y requiere se explicado: la exomologesis ${ }^{2}$.

Según Foucault, en la práctica monacal la penitencia era un elemento central, pero no estaba sola sino que contenía a la exomologesis entendida como la demostración del pecado. "No hay penitencia sin la actividad consciente de exhibir, mostrar, expresar manifestar.” (Foucault, 2013, p.126)

\footnotetext{
2 El término acepta diversos usos que van desde una traducción de la confesión jurídica, el reconocimiento ante dios como pecador, pero refiere al reconocimiento de los propios pecados.
} 
Explicando este concepto nos brinda la siguiente imagen:

cuando uno va a un médico, debe mostrarle sus llagas para que él las cure, de la misma manera, si queremos curarnos de los pecados que hemos cometido, debemos mostrar nuestras llagas a quien debe curarnos, el christus medicus, que es quien nos curara y nos llevará a la salvación. Encontramos asimismo argumentos de tipo judicial bajo esta forma: cuando uno quiere conseguir que el juez lo perdone, sabe muy bien que si confiesa y reconoce humildemente su falta, apaciguara al juez. ${ }^{3}$. (Foucault, 2013, p. 126)

La exomologesis es entonces un acto de exhibición, pero esa exhibición no tiene como destinatario al otro, sino al propio sujeto, quien mediante el acto de mostrar sus llagas, toma consciencia de su existencia. Sin embargo, el "otro" es imprescindible pues la exhibición ante ese "otro" es parte necesaria del rito. No es un acto de contracción personal, o de análisis de la propia acción en el fuero intimo (practicado en otros momentos y culturas) pues si bien el acto contiene ese acto íntimo, requiere también de manera ineludible la exteriorización, la exhibición ante el otro.

Analizando el desarrollo de estas prácticas en distintos momentos históricos de Europa, Foucault (2013) señala que:

en el monacato, el decir veraz sobre sí mismo se convirtió en un elemento absolutamente fundamental, esencial de esa vida, y en definitiva se inyectó, se injertó, se implantó en una forma absolutamente novedosa dentro de la cultura occidental. A partir de allí, la práctica de la confesión, la muy compleja tecnología de veridicción de sí mismo, va a tener una fortuna considerable. (Foucault, 2013.144)

\footnotetext{
${ }^{3}$ No es casual que el "arrepentimiento" esté establecido como un elemento para disminuir la pena del culpable. Hasta el último momento el sistema el pide al acusado que confiese, para así obtener una mejora de su situación.
} 


\section{LA DEMANDA DE CONFESIÓN Y EL PROCESO PENAL}

Durante esta etapa sin embargo la cuestión del poder, jurisdiccional o de la iglesia, permanece todavía ausente, y el acto se mantiene en el fuero íntimo, privado.

\section{Los cambios comienzan cuando la confesión se inserta dentro de una} relación de poder, primero en el seno de la misma iglesia y luego como poder jurisdiccional, cuestión que, por esos años, era muchas veces confuso y de límites difusos.

En el monacato: la veridicción es un proceso; la veridicción de sí mismo - el decir verdad sobre si - es una condición indispensable para la sujeción a una relación de poder con el otro. Y de pronto, el otro va a escuchar, y quien está sometido va a hablar. (Foucault 2013, p.157)

El decir verdad sobre sí mismo para poder obedecer y llegar al estado de obediencia implica dos etapas: primero, auto examinarse, y segundo, decirlo verbalmente, expresarlo. Por eso la veridicción es un acto verbal.

Esta práctica que surgió de los monjes cristianos primitivos fue luego juridizada en un proceso que duró varios siglos que, afirma Foucault, alcanza su punto culminante en el Concilio de Letrán de 1215, en el cual se establece la obligación de los cristianos de confesarse, como mínimo, una vez al año, en Pascuas (Foucault 2013, p 201).

Este cambio es fundamental pues, hasta allí, la confesión estaba vinculada al pecado (como he pecado me confieso); pero al ser establecida como un acción periódica y obligatoria, pierde ese vínculo con el pecado (con la falta, la infracción) y se convierte en una parte de la institución eclesiástica.

Como soy cristiano, pertenezco a la iglesia, como pertenezco a la Iglesia, debo confesarme en Pascua. Si no me confieso en Pascua dejo de ser cristiano, Tal es la lógica que subyace en esta juridización de la confesión que se convierte así en requisito de permanencia dentro de la Iglesia. 
En la clase del 13 de mayo de 1981 analiza también Foucault el proceso de cambio que afectó el modo de hacer la confesión; y la relación física entre el confesante y el confesor. Siendo un acto oral la cercanía física es imprescindible, y por ello surgió también la necesidad de reglamentar el modo de ese encuentro.

Los confesionarios recién aparecen en el Siglo XVI y señala Foucault que:

la importancia de lo físico, la necesidad de ver (por parte del confesor además) a quien estaba confesándose, tenía también otra razón de ser: debía permitir también al confesor descifrar, a través de la actitud del confesado, lo que este podía eventualmente ocultar o tenía vergüenza de decir”. (Foucault 2013, p. 206)

Vemos así como el proceso de juridizacion de la confesión lleva a cambiar su naturaleza (pues ya no es la exomologesis como acto de exposición y toma de conciencia) sino un acto de sometimiento a otro que nos juzga y perdona.

Pero también cambia el rol el rol de quien la recibe la confesión. Deja de ser un mero testigo, un observador que sirve al confesante para exhibir su pecado, sino que por el contrario asume un rol activo de verificación de la "corrección" y completitud de la confesión, de la efectiva veridicción del sujeto confesante.

Se manifiesta en el otro el principio de autoridad, pues el otro no solo cumple el rol de observador, sino que interviene en el acto mediante la verificación de veridicción y, eventualmente, la imposición de la penitencia, el castigo.

En este punto la confesión deja de ser un acto religioso, de vinculación con un dios impersonal, para insertarse en una estructura de poder religioso y jurisdiccional.

Es decir que la confesión como práctica religiosa evolucionó desde un acto personal de arrepentimiento del pecado cometido, hasta una práctica de pertenencia institucional; pasando por etapas donde requería ese acto personal de constricción pero también exigía su exhibición ante el confesor. Pero también cambio el rol del otro 


\section{LA DEMANDA DE CONFESIÓN Y EL PROCESO PENAL}

sujeto, pasivo primero, mero instrumento del confesante necesario para la exhibición de la falta; a un confesor que investiga sobre la veracidad del pecado y del arrepentimiento, y perdona o castiga como parte de una institución de poder.

\section{LA CONFESIÓN EN LA INQUISICIÓN}

Como no podía ser de otro modo estas prácticas religiosas, pero juridizadas, se trasladaron, con especial énfasis, cuando la Iglesia juridiza el control de la pureza del pensamiento, las prácticas y el compromiso religioso, mediante la creación de los tribunales de la Inquisición.

Sigamos al hombre, detenido en la noche. Arrancado del sueño bruscamente, vestido a toda prisa, baja la escalera, sigue por las negras callejuelas donde los pasos de los familiares de la Inquisición resuenan con ecos lúgubres. Llega a la casa Santa - ese el nombre de las oficinas inquisitoriales - siempre tratado con una gélida cortesía, sin brutalidad. El proceso empieza ceremoniosamente con la prestación del juramento de los evangelios. Luego viene el interrogatorio. Tendrá que dar detalles sobre su familia, su vida, sus costumbres, sus amigos y conocidos. ¿Por qué ha sido detenido? Si responde que no lo sabe, tampoco le dirán nada, pero continuaran haciéndole preguntas vagas que tendrá que sortear siempre con el temor de una trampa. A propósito ¿Quién es su confesor? ¿Cuándo se ha confesado por última vez? Las preguntas se suceden una tras otra durante horas en el mismo tono...El inquisidor sigue las famosas Instrucciones de Torquemada. ... que dice: 'si alguien que haya sido denunciado y convicto del pecado de herejía lo niega y persiste en sus denegaciones hasta que la sentencia sea pronunciada, y si el crimen ha sido pronunciado contra él, aunque confiese la fe católica y afirme que siempre ha sido cristiano y que sigue siéndolo, los inquisidores lo declararan hereje y lo condenaran como tal, porque el crimen ha quedado probado jurídicamente y por su negativa a reconocer su error el 
condenado no permite a la Iglesia absolverle y usar de misericordia con él. (Dominique, 2002, p.164)

La descripción novelesca que realiza Dominique muestra claramente el rol central que tenía la confesión en el proceso inquisitorial, y no nos alejamos de la realidad si aseveramos que es, casi exclusivamente, un proceso reglamentario de la confesión.

El rol de los testigos era virtualmente inexistente y las reglamentaciones al respecto, totalmente absurdas y auto contradictorias. Así las prostitutas, criminales y excomulgados podían ser testigos de cargo de la inquisición, pero no de descargo del acusado. O sea que solo se aceptaban aquellos testigos que coincidieran con la acusación.

Además en la práctica "Un testigo que deponga a favor de un hereje resulta inmediatamente sospechoso" (Dominique, 2002. pág. 164) lo cual no parece que hubiera podido ser un aliciente para incorporar versiones alternativas a la del Inquisidor, por lo cual es indiscutible que los aportes reales de los testigos en el proceso inquisitivo eran, en verdad, inexistentes. Todo se centraba en la confesión.

Esta trascendencia de la confesión en la Edad Media la señala también Foucault en la clase del 20 de mayo de 1981. Describe el proceso ya analizado antes (origen monacal de la práctica con su posterior juridizacion), sin embargo apunta que "la importancia asumida por la confesión en la práctica judicial de la Edad media es el efecto de modificaciones que eran propias de las instituciones de justicia” (Foucault, 2014, p. 217) incorporando así al análisis del tema la evolución de las instituciones judiciales propiamente dichas. 


\section{LA DEMANDA DE CONFESIÓN Y EL PROCESO PENAL}

Lo que Foucault deja claramente expuesto, como proceso histórico surgido de la institución religiosa, es la necesidad que han tenido tradicionalmente los sistemas de enjuiciamiento penal de que exista la confesión del acusado. El uso del artículo "la" no es casual, pues no se exige "una" confesión, sino "la" confesión", es decir, la corroboración de la hipótesis fáctica sostenida ex ante por el sistema de juzgamiento penal.

Durante los siglos XVIII y XIX en paralelo a los cambios políticos caracterizados por la disminución de la influencia religiosa en las instituciones públicas y el cuestionamiento al absolutismo monárquico, se produce también una evolución del proceso judicial, y un retroceso de la inquisición, no como modelo jurídico cultural pero si como institución judicial de control social.

El surgimiento del fenómeno científico, fundado en la confianza de la razón para explicarlo todo, incluso el delito y los impulsos humanos que llevan hacia él, se introdujo fuertemente en las instituciones jurídicas y, como consecuencia, cambia la concepción del proceso y del delito, pero también la mirada sobre el infractor.

Sin embargo estos cambios no se traducen en el abandono de la búsqueda de confesión. Aunque se resignifique su finalidad y sentido, en la cultura jurídica continental sigue vigente esa demanda de confesión.

La evolución de los estudios médicos y psiquiátricos primero y la aparición de la criminología en la segunda mitad del Siglo XIX, tratan de entender al delincuente,

\footnotetext{
${ }^{4}$ Cuando el inquisidor acusa a Rebeca de bruja y de practicar actos satánicos, la única confesión aceptable es que Rebeca diga: "soy bruja y practico actos satánicos". Cualquier otra confesión (mate a Juan y arroje su cadáver al rio) no tendrá trascendencia alguna y será negada o señalada cono un modo de distraer al inquisidor. Por supuesto que la negativa tampoco es aceptada.
} 
creen, postulan y buscan el método para curar de curar al delincuente, el cual es ahora visto como una manifestación de una enfermedad social.

Pero esa curación requiere también la confesión, la aceptación del hecho, pues de lo contrario es imposible. No se puede curar a quien no acepta que cometió la infracción y tiene consciencia del mal hecho. Por supuesto que también cambien los métodos, la tortura no es ya admisible, por lo menos como método científico aunque persista como sistema de investigación criminal, pero la demanda de confesión, de veridicción, persiste.

El lugar del acusado sigue siendo el mismo. Se halla frente al poder y ese poder le pide, ahora más amablemente pero con igual firmeza, que confiese, que diga la verdad. No para que la Iglesia lo absuelva "misericordiosamente" y, a cambio de la salvación eterna, ser entregado al brazo secular del poder real; como postulaba la Inquisición; sino para comprenderlo, para curarlo, para rehabilitarlo y reinsertarlo en la sociedad.

De este modo, racionalizada y - en alguna medida - humanizada en cuanto a sus métodos; la demanda de confesión se reinserta en las organizaciones jurídicas gestadas en ese periodo que modelan el sistema europeo continental y que se trasladará, pese al mandato constitucional en contra, a nuestras instituciones nacionales.

Por eso la demanda de confesión, iniciada como una práctica monacal de naturaleza religiosa, juridizada en la inquisición, se traslada a la justicia penal, resignificada en cuanto a sus modos y objetivos, pero con igual certeza de su necesidad.

Si bien ahora ya no se exige la confesión para absolver del pecado, igualmente el sistema pretende obtener esa confesión para entender al delincuente, curarlo y devolverlo a la sociedad. 


\section{LA DEMANDA DE CONFESIÓN Y EL PROCESO PENAL}

Sin embargo esto no arrojó los resultados esperados pues Foucault señala que este traspaso de la "salvación" religiosa al ámbito de la justicia laica no cumplió con lo esperado, explicando que si "la confesión... ya no funciona, es porque consiste en una confesión muy distinta dentro de una maquinaria penal muy distinta. Esa es la curva...primero, institucionalización de la confesión en la práctica judicial, en segundo lugar, desarreglo de la maquina penal por el efecto de la práctica de la confesión" (Foucault 2014, p. 219) pues, pese a sus proclamas y buenas intenciones, la realidad es que el sistema de juzgamiento penal no sabe qué hacer frente a casos donde la razón no logra explicar el delito ni al delincuente, el reconocimiento de la infracción no alcanza para el arrepentimiento y no siempre la rehabilitación y reinserción es posible. Este fracaso, sin embargo, no proscribió la búsqueda de la confesión que persistió en el sistema.

La significación de la confesión ha cambiado con el transcurso y evolución de las instituciones jurídicas, sin embargo aún en los sistemas modernos persiste esta necesidad sistémica de la confesión, aunque se haya resignificado.

Foucault sintetiza en tres apartados los diferentes significados dados a la confesión, cambios de significación que explican su persistencia en el sistema de justicia aun cuando fueran cambiando los sistemas políticos, los regímenes jurídicos y aun las escalas axiológicas:

a) reconocer a través del reconocimiento de ese crimen, la validez del castigo que uno va a sufrir. ... la confesión del culpable puede (y en términos de derecho estricto y no, de modo alguno, de psicología) rubricar el castigo que lo cercena del cuerpo social o lo despoja de sus derechos; al mismo tiempo, esa confesión va marcar el primer jalón de su reintegración. (Foucault, 2014, p. 225) 
b) Su importancia respecto al régimen de verdad al cual se halla sometida la investigación criminal. Habiendo desaparecido el sistema de pruebas tasadas, que hacia descansar en preceptos abstractos la reconstrucción de la verdad de lo sucedido, con el actual sistema de libre convicción, queda en las manos, o mejor dicho, en su mente y en su espíritu, juzgar sobre lo que en verdad sucedió. En este contexto "la importancia de la confesión como prueba irrefutable" (Foucault, 2014, p. 226) pues ella, y solo ella, puede dar al juez o al jurado la tranquilidad absoluta de haber hecho justicia.

c) Porque si no existe confesión queda en duda una de las finalidades esenciales del castigo: la enmienda. Si el castigado no reconoce su crimen el proceso de sanación que el sistema penal postula (pues la pena ya no solo pretende castigar sino también corregir y enmendar al infractor) queda trunco. "El castigo, en consecuencia, debe ser corrector, y la confesión, como manera de reconocerse culpable, constituye el primer elemento..." (Foucault, 2014, p.227).

La demanda de confesión ha surcado la historia de las instituciones judiciales de la cultura occidental, modelándolas e influyendo sobre ellas de manera notoria.

Muchos aspectos de esta influencia han estado fuertemente vinculados a las formas utilizadas para la confesión pues la misma se halla directamente influenciada por el modo de realizarse.

Recordemos que la confesión no es solo el acto de autoexamen, requiere la verbalización, por lo cual la forma y el contenido se complementan e influyen, al extremo que es imposible concebirlos separados.

Dos imágenes literarias muestran este vínculo entre la forma y el contenido.

El inquisidor está sentado en la silla, tras la mesa en que reposan el crucifijo y los evangelios. En el extremo de la mesa, el notario va tomando nota de las preguntas y 


\section{LA DEMANDA DE CONFESIÓN Y EL PROCESO PENAL}

respuestas. Tomará nota también de todos los gestos del verdugo y del inculpado, todo los detalles del suplicio. ...El inquisidor empieza a interrogar. El acusado no habla. Entonces el verdugo tira suavemente del extremo de la cuerda y los brazos se alzan. El hombre se curva para escapar del dolor, pero el verdugo sigue tirando, y el dolor persiste, aumenta y quiebra los hombros del desgraciado. Pero este sigue sin hablar... Frente a él, el inquisidor, inmóvil lo observa todo. (Dominique, 2002, p.170)

Tenemos aquí un punto importante que hay que señalar en la historia del pensamiento penal: el momento en que la demanda de confesión... es reemplazada y duplicada por una demanda de otro tipo. Para el juez ya no se trata de decir lo que decía implícitamente en épocas pasadas: 'dime si, en efecto, has cometido el crimen del que se te acusa'... Ahora el juez hace implícitamente esta pregunta a quien está acusando: “dime quien eres, para que yo pueda tomar una decisión judicial que tendrá que estar a la altura de crimen que has cometido, claro está, pero también del individuo que eres. (Foucault, 2013, p 244)

Pese a las distancias que presentan esas imágenes, sin embargo, son mayores las coincidencias que nos interesa destacar. En ambos casos un ciudadano acusado que comparece ante un juez para hablar, para decir, para confesar. Los contenidos han cambiado, y también los modos, pero el objetivo sustancial del acto parece inmutable a lo largo de los últimos siglos.

\section{EL NUEVO PARADIGMA. ¿HA DESAPARECIDO LA DEMANDA DE CONFESIÓN?}

Nuestros sistemas procesales, los recientes y aun muchos vigentes, ponen el acto de la indagatoria como uno de los momentos centrales del proceso, tanto en la etapa instructoria como en el juicio oral. Si bien es innegable que hemos civilizado en algún grado este acto, al haber establecido que debe estar precedido del acto de imputación poniendo en conocimiento del acusado el hecho por el cual está siendo acusado; no 
menos cierto es que el objetivo sustancial de este acto sigue siendo lograr que el imputado confiese y, de esta forma, legitime la sospecha del sistema.

La demanda de confesión del sistema de justicia al imputado es una exigencia surgida de las prácticas religiosas que, juridizada, se ha trasvasado a los sistemas de justicia y que ha persistido a lo largo de siglos habiéndose constituido en un elemento esencial para la legitimación del propio sistema y de la aplicación de pena. La aplicación y reglamentación de la garantía de no ser obligado a declarar en contra de sí mismo en países como el nuestro, fuertemente influenciados por ese sustrato cultural, adquiere una especial relevancia.

Sin embargo los códigos adversariales modernos adoptados en nuestro País (Chubut - Neuquén - Provincia de Buenos Aires) y más recientemente el Código Procesal Penal de la Nación Ley 27.063, han eliminado la declaración del imputado como acto susceptible de realizarse por mandato legal o a petición de la acusación. La declaración del imputado acusado es un acto que solo existe en caso que el imputado así lo decida.

El artículo 69 del Código Procesal Penal, consagra como principio la Libertad de declarar y establece que "Las citaciones al imputado no tendrán por finalidad obtener una declaración sobre el hecho que se le imputa, pero éste tendrá la libertad de declarar cuantas veces quiera”. En similar sentido el artículo 261 que reglamenta el inicio del debate en el juicio oral, no prevé la declaración del imputado, sino que se limita a señalar que "En el curso de la audiencia, el imputado podrá hacer todas las declaraciones que considere oportunas. Las partes podrán formularle preguntas o requerirle aclaraciones." Como vemos, no hay citación ni emplazamiento, y en ningún 


\section{LA DEMANDA DE CONFESIÓN Y EL PROCESO PENAL}

momento el imputado debe expresar su voluntad de abstenerse. Simplemente si decide declarar, declara.

Por ello afirmamos que los códigos adversariales y acusatorios han realizado un abandono de la pretensión estatal de obtener la confesión; y este renunciamiento se ha manifestado de manera efectiva en la reglamentación procesal de la declaración del imputado. Por ello estas nuevas normas procesales hacen efectiva de manera real, y no meramente declamativa, la garantía de no ser obligado a declarar contra sí mismo en el proceso penal; pues a reglamentación no se limita a consagrar la posibilidad de abstención de declarar ante la citación a hacerlo, sino que establecen como nuevo paradigma la inexistencia misma de la citación a declarar.

Y este cambio impacta sobre la conceptualización del proceso y de la pena. Ya no es imprescindible para el proceso lo que el acusado pueda decir sobre sí mismo. Sus motivos o su arrepentimiento. Si desea puede hacerlos valer, puede explicarse, justificarse y defenderse. Se le dan todas las garantías y tiene la oportunidad de hacerlo, pero no es imprescindible. No se lo pide el sistema de juzgamiento penal. Es su derecho y su decisión.

Este abandono de la demanda de confesión es consecuencia de la reconstrucción de la cultura acusatoria y adversarial que, en el mejor sentido, quita del centro de la escena al imputado y pone allí al conflicto interpersonal. Foucault (2014) ya había advertido la vinculación existente entre el abandono del paradigma acusatorio y la necesidad de la confesión explicando que:

... el crecimiento del poder monárquico dentro de contexto de las instituciones feudales se apoyó en el ejercicio y el desarrollo del poder judicial. Cuando afianza su poder por encima del poder feudal o en los intersticios del poder feudal el rey lo hace en cuanto juez, en cuanto arbitrio, en cuanto se recurre a él para zanjar litigios o cuando el mismo 
inicia causas que quiera resolver. Y el rey toma sus decisiones y las hace en la forma jurisdiccional. En síntesis... la primera forma del estado moderno, fue un Estado de justicia. .. A medida que el poder político y el poder jurisdiccional se imbrican de ese modo, resulta evidente que las formas de los procedimientos jurídicos se modifican. En especial, el procedimiento acusatorio con que alguien, la víctima o bien aquel que la representaba, acusaba a otro de haberle causado un daño... (p. 220)

Por ello la aparición del soberano como mediador del conflicto, cambia todo. Cuando la resolución está en manos del rey, este buscará establecer "la verdad” y decidir una sanción en función de esos hechos establecidos.

La necesidad de una veridicción se inscribe en el desplazamiento que lleva a la justicia penal a remontarse... de la resolución del conflicto en la forma de un enfrentamiento entre dos individuos a la resolución de un conflicto en la forma de una decisión de una corte soberana o la decisión del soberano..$^{5}$ (Foucault, 2014, p. 221)

Sin embargo el sistema de administración de justicia seguirá exigiendo la confesión, pues servirá para la confirmación de la justicia de la decisión adoptada y, en consecuencia, legitimará la resolución del soberano.

Aun cuando haya una verdad establecida por la resolución del soberano, aun la confesión es necesaria, no ya para decidir la sanción que ya se impuso, sino para legitimar el sistema.

Así analizado y conceptualizado guarda absoluta coherencia, histórica y filosófica, que junto con el abandono de la cultura y las instituciones judiciales inquisitivas retroceda también la demanda de confesión, y que el resurgimiento y

\footnotetext{
${ }^{5}$ Foucault realiza aquí un análisis muy interesante sobre la vinculación entre la tortura y la confesión, y como eso se enlaza con el procedimiento acusatorio primitivo, el duelo judicial, y como el nuevo procedimiento inquisitivo incluye de alguna manera resabios del mismo. El acusado como objeto y a la vez como prueba el mismo (ver pag. 221/222). No profundizamos ese aspecto por exceder nuestro objeto.
} 


\section{LA DEMANDA DE CONFESIÓN Y EL PROCESO PENAL}

recuperación del paradigma acusatorio se manifieste en el abandono de la pretensión de veridicción del acusado, pues la misma ya no es necesaria para el sistema.

Queda así en evidencia que la recuperación del paradigma acusatorio para regir y modelar nuestro sistema de juzgamiento penal por mandato constitucional, se traduce en el abandono de la demanda de confesión y ello conlleva la re significación profunda del rol del imputado en el proceso penal y la conceptualización de éste.

En la demanda de veridicción, tanto la religiosa como la judicial, subyacía una transacción. "Dime que has pecado, y te daré la vida eterna". "Dime que has delinquido y te curare." Dame eso que necesito para confirmar mi verdad, legitimar el sistema y saber cómo piensas, para que pueda curarte, o sea dame la confesión, y tendrás un beneficio.

La reformulación de la declaración del imputado, el abandono de la pretensión de confesión se desentiende de ese intercambio. Nada te pido, pero nada te debo.

Lo que legitima la verdad surgida del proceso no será el reconocimiento del imputado del hecho, sino la reconstrucción del relato por el juego adversarial y de confrontación que el sistema acusatorio instituye.

El sistema acusatorio moderno no requiere la confesión pues no necesita legitimar el castigo a través de la aceptación de la infracción, sino que el misma se funda en la legitimidad democrática del sistema de administración de justicia. Podemos discutir la raíz filosófica de esta justificación, y sin duda encontraremos voces en contra, pero desde la perspectiva intrínseca del sistema político constitucional, es la legitimidad democrática del poder lo que autoriza el ejercicio de la violencia estatal sobre el condenado, y la aceptación de este resulta irrelevante, por lo cual su confesión no es trascendente. 
Tampoco necesita, ni le pide al imputado, que confirme la verdad surgida del proceso, pues "la tranquilidad del juez de haber hecho justicia" se fundamenta en lo adversarial, en el debido proceso, en la transparencia del sistema de investigación y, sobre todo, en la posibilidad real y efectiva del ejercicio de la contradicción y el derecho de defensa. La verdad reconstruida en el proceso surge así con legitimidad, y con prescindencia de la convalidación por el acusado de esa verdad.

Por último también se abandona la pretensión de arrepentimiento como base la enmienda. No porque se prescinda de la rehabilitación como finalidad, aunque este concepto se halle en crisis en cuanto que el sistema penal esté en condiciones o pueda contribuir de manera efectiva a concretar o colaborar con ese objetivo, pero en todo caso no hay dudas que ese acto de constricción y autoexamen que es la confesión, en tanto reconocimiento de la falta y arrepentimiento a través de la veridicción, no se hallan en el ámbito del derecho y, en todo caso, deberá ser analizado por la psicología, la moral, la religión o como parte de la problemática de la criminología.

Hemos intentado demostrar que las implicancias que tienen los cambios en el proceso penal, expresado en los códigos procesales que siguen el modelo constitucional de juzgamiento penal, tal como el nuevo código procesal penal nacional Ley No. 27.063; van mucho más allá de la re significación de roles, cambios de funciones, o modificación de trámites, sino que por el contrario se trata de adoptar la cultura acusatoria y adversarial, desplazando la inquisición, a la cual no solo encontramos manifiesta y evidente en los tramites, sino en el sustrato y sustento de cada una de nuestras instituciones y nuestras prácticas cotidianas.

La recuperación de la cultura acusatoria, en toda su extensión y en todas sus manifestaciones y derivaciones, es una deuda pendiente que tenemos con los 


\section{LA DEMANDA DE CONFESIÓN Y EL PROCESO PENAL}

constitucionalistas del siglo XIX, con Alberdi y los padres fundadores de la Constitución Nacional de 1853 que, de todos los modos posibles, nos encomendaron el abandono del modelo inquisitorial.

Sin embargo nuestra deuda es aún más antigua, y se origina en 1813 con la proscripción de la Inquisición por la Asamblea del Año XIII y la quema en la plaza pública de los instrumentos de tortura que integraban su patrimonio.

Instrumentos que, no casualmente, tenían como único objetivo obtener la confesión. Con la aprobación de la Ley $N^{\circ} 27.063$ hemos comenzado a pagar esa deuda histórica. Por delante quedan enormes desafíos.

\section{REFERENCIAS BIBLIOGRÁFICAS}

Dominique, P. (2002). La inquisición (3 ${ }^{\mathrm{a}}$ ed.). Barcelona, España: Luis de Caralt Editor S.A.

Foucault, M. (2014). Obrar mal, decir la verdad: La función de la confesión en la justicia. Curso de Lovaina 1981(H. Pons, trad.). Buenos Aires: Siglo XXI Editores.

Ley N²7.063 Nuevo Código Procesal Penal de la Nación.

YourDictionary. Recuperado de http://www.yourdictionary.com/

Oxford University Press. (s.f.). Oxford Dictionaries. Recuperado de http://www.oxford dictionaries.com/es/

\section{Curriculum vitae}

ABOGADO (1986). ESPECIALISTA EN DERECHO PROCESAL (2003). Actualmente es doctorando en Derecho (2da. Cohorte) con Plan de Tesis aprobado y en 
elaboración.

Desde el año 2010 ejerce la docencia de posgrado en Derecho Procesal Penal y ha dictado numerosos cursos de Capacitación en Litigación Oral y Procesos de Reforma procesal penal en diversas provincias argentinas y también en Latinoamérica (Cuba, Panamá, Perú, Paraguay) actuando como Consultor de programas de reforma hacia el sistema acusatorio.

Ha publicado los siguientes Libros "INTRODUCCION AL PROCESO ACUSATORIO Y LA LITIGACIÓN ORAL" MAVE, Corrientes 2012, EL FISCAL DE ESTADO EN LAS PROVINCIAS ARGENTINAS" EDITORIAL MAVE, Corrientes 2010, "HONORARIOS PROFESIONALES). MAVE, Corrientes 2001. CODIGO PROCESAL PENAL MODELO DEL NEA. "CENTRO DE CONTENCIÓN JUVENIL DE CORRIENTES “Un modelo constitucional para la contención educativa y de seguridad de jóvenes en conflicto con la ley penal institucionalizados por orden judicial”. Buenos Aires, 2010. Es autor del Código Procesal Penal Modelo del NEA y del Proyecto de Código Procesal penal para la Provincia de Formosa.

Correo electrónico: carbajal355@ hotmail.com 